\title{
Mapas de risco: uma alternativa para o planejamento de controle de incêndios florestais
}

\author{
Antonio Carlos Batista
}

Palavras-chave: incêndios florestais, prevenção, zoneamento de risco

\section{INTRODUÇÃO}

As notícias sobre as ocorrências de incêndios florestais no Brasil e em outras partes do mundo, causando alterações drásticas no ambiente e danos econômicos importantes, ressaltam a necessidade de se adotar mecanismos para reduzir o número de incêndios e a extensão dos danos.

A alternativa utilizada pela maioria dos órgãos responsáveis pela proteção dos recursos naturais é a adoção de técnicas e medidas de prevenção dentro de uma política adequada de planejamento de distribuição dos recursos destinados à proteção contra incêndios florestais.

$\mathrm{O}$ zoneamento de risco ou os mapas de risco de incêndios têm sido empregados cada vez mais como instrumentos fundamentais no planejamento racional dos recursos destinados à prevenção e pré-supressão dos incêndios florestais.

Esse artigo tem o objetivo de descrever as etapas necessárias para o desenvolvimento de um mapa de riscos de incêndios, demonstrando a viabilidade e importância desse instrumento no planejamento do controle de incêndios florestais. 


\section{MAPAS DE RISCO}

A importância de se elaborar mapas de risco de incêndios florestais tem sido evidenciada há muito tempo (SHOW \& CLARKE, 1953). Esses mapas, bastantes simples, eram resultado da plotagem das áreas atingidas pelos incêndios em um mapa base, através de informações obtidas de relatórios de incêndios de anos anteriores. Desse modo, com os registros de vários anos, era definido um padrão para as áreas de maior ocorrência e eram traçados limites que as caracterizavam como áreas especiais de risco (BROWN \& DAVIS, 1973; CHANDLER et al., 1983; SOARES, 1996).

Atualmente, com a maior disponibilidade dos recursos, vários pesquisadores têm desenvolvido zoneamento de risco de incêndios florestais utilizando metodologias que permitem associar os fatores ambientais de uma região com os incêndios florestais, possibilitando dessa forma mapear o risco potencial de incêndios dessa região em função da sensibilidade dos fatores analisados em relação ao fogo (MACEDO \& SARDINHA, 1987; SALAS E CHUVIECO, 1994; SOUZA et al., 1996; SMITH, 1999).

\section{FATORES DE RISCO}

A ocorrência e propagação dos incêndios florestais em uma região dependem de vários fatores associados ao fenômeno da combustão. Esses fatores, por sua vez, variam em função do ambiente, influenciando de maneira distinta a combustão, resultando numa diversificação da ocorrência e propagação dos incêndios, de acordo com as características do ambiente.

De uma maneira bem simplificada pode-se dizer que a probabilidade do fogo ocorrer e se propagar em um determinado local é função da probabilidade de haver uma fonte fogo e da probabilidade de haver condições favoráveis para esse fogo se propagar (SOARES, 1985). A análise criteriosa desses dois grupos de fatores - fonte de ignição e condições favoráveis de propagação - possibilita avaliar o potencial de risco de incêndios de uma região, isto é, permite estabelecer potencialmente onde e como o fogo vai se propagar.

No grupo denominado fontes de fogo estão incluídas as atividades que geram a faísca ou a chama inicial para desencadear o processo de combustão. As condições favoráveis de propagação representam todos os fatores do ambiente que influenciam direta ou indiretamente o desenvolvimento do fogo em uma determinada região. 


\section{FONTES DE FOGO}

As estatísticas sobre as ocorrências de incêndios florestais no Brasil e outros países mostram que a maioria dos incêndios iniciam a partir de fontes de fogo decorrentes direta ou indiretamente das atividades humanas, ou seja, a grande maioria dos incêndios florestais são provenientes de causas humanas.

A caracterização criteriosa das atividades de uso e ocupação da terra pelo homem, relacionando-as com o potencial de produção de fontes de fogo é fator fundamental para o zoneamento de risco de incêndios.

A análise das causas dos incêndios, através dos registros de ocorrência de incêndios florestais, é uma forma simples e prática de avaliar o grau de risco em função das principais fontes fogo. De acordo com a FAO (SHOW \& CLARK, 1953), as principais causas dos incêndios que ocorrem no mundo podem ser agrupadas nas seguintes categorias: raios, incendiários, queimas para limpeza, operações florestais, fumantes, fogos de recreação, estradas de ferro e diversos. Pode-se observar que apenas o grupo de causas "raios" não é de responsabilidade humana. Todas as demais decorrem de atividades humanas. As estatísticas mais recentes sobre incêndios florestais no Brasil indicam que, de acordo com a classificação da FAO, as principais causas dos incêndios florestais são "queimas para limpeza" e "incendiários" (SOARES, 1996).

O zoneamento em função das fontes de fogo de origem humana pode ser feito indiretamente, através de variáveis associadas com o nível de atividades humanas ou nível de antropismo, como por exemplo, rede viária, demografia, infra-estruturas, etc. (ALMEIDA, 1994; SOUZA et al. 1996; CHOU et al., 1999).

\section{FATORES DE PROPAGAÇÃO}

Diversas características do ambiente têm forte influência sobre o início, a propagação e a intensidade dos incêndios florestais. Os fatores mais relacionados com os incêndios são: o material combustível, as condições climáticas, a topografia e o tipo de cobertura vegetal (BROWN \& DAVIS, 1973).

\section{- MATERIAL COMBUSTÍVEL}

Material combustível florestal pode ser definido como qualquer material orgânico, vivo ou morto, no solo ou acima deste, capaz de entrar em ignição e queimar. $\mathrm{O}$ material combustível é fundamental para a ocorrência e propagação do fogo porque é um dos componentes do triângulo do fogo - não há possibilidade de ocorrência de fogo se não houver combustível para queimar. Dentre as características dos combustíveis que mais influenciam a 
ignição e a propagação dos incêndios destacam-se: a quantidade, a umidade, a inflamabilidade, a continuidade e a compactação (RIGOLOT, 1990).

A quantidade de material combustível existente em uma área indica se o fogo vai se propagar ou não e determina a quantidade de calor que será liberada na queima. Nem toda vegetação existente numa área é combustível. A quantidade que está disponível para queimar é denominada "combustível disponível" e depende de várias outras propriedades, tais como: a proporção entre material morto e vivo, o tamanho médio das partículas de combustível e o conteúdo de umidade (ANDERSON \& BROWN, 1988).

O conteúdo de umidade é a mais importante propriedade que controla a inflamabilidade dos combustíveis vivos e mortos. A umidade do material combustível reflete o clima e as condições meteorológicas do local, podendo variar rapidamente. Combustíveis vivos e mortos têm diferentes mecanismos de retenção de água e reagem distintamente às variações das condições meteorológicas. O conteúdo de umidade dos combustíveis mortos flutua principalmente em função da umidade relativa, temperatura do ar e precipitação. Partículas finas do combustível morto, tais como: folhas secas e pequenos ramos podem variar o conteúdo de umidade em poucas horas. Ao contrário, são necessários vários dias ou semanas para variar significativamente o conteúdo de umidade de um tronco de árvore ou galho caído (SCHROEDER \& BUCK, 1970). O conteúdo de umidade da vegetação viva varia principalmente em resposta ao estágio estacional de desenvolvimento em que se encontra. Geralmente, durante a estação de crescimento, as árvores apresentam muita brotação e folhas novas e portanto apresentam um conteúdo de umidade bastante elevado, podendo chegar $300 \%$ do peso seco. No início do inverno, quando as árvores começam a entrar em dormência, apresentam teor de umidade próximo de $50 \%$ (SOARES, 1985).

A inflamabilidade está associada às seguintes características do combustível: estrutura, teor de umidade, composição mineral, presença de substâncias inflamáveis e estado fisiológico (RIGOLOT, 1990). Normalmente, à medida que aumenta a proporção de combustível fino morto, tais como: folhas, acículas, e pequenos ramos, aumentam a inflamabilidade do material combustível. Isto ocorre porque quanto mais fina for a partícula de combustível mais rápida é a troca de calor e umidade entre o combustível e o ambiente.

A continuidade do combustível refere-se à sua distribuição sobre uma área, tanto no sentido horizontal quanto vertical. É uma característica muito importante porque controla parcialmente onde o fogo pode ir e a velocidade com que se propaga. Quando o material está distribuído uniformemente sobre uma área, não há interrupção no combustível e as chamas irão se propagar sem obstáculos. Quanto à continuidade não é uniforme, isto é, quando o combustível está disposto de forma dispersa, há dificuldade do fogo se propagar devido às interrupções do combustível sobre a área (ANDERSON \& BROWN, 1988). 
A compactação refere-se ao espaçamento entre as partículas do combustível. É expresso normalmente em peso por unidade de volume do combustível depositado na superfície da floresta. A melhor maneira para reduzir a inflamabilidade pela alteração da compactação é compactar os combustíveis finos e separar ou espalhar os combustíveis grossos (BATISTA, 1990).

\section{- $\quad$ CONDIÇÕES CLIMÁTICAS}

As florestas e os incêndios florestais são fortemente afetados pela variação climática. Elementos meteorológicos, tais como: temperatura, umidade relativa, vento e precipitação, têm efeitos característicos sobre o comportamento do fogo, influenciando decisivamente a ignição e a propagação dos incêndios.

$\mathrm{O}$ vento afeta o comportamento do fogo de várias maneiras. $\mathrm{O}$ vento leva para longe o ar carregado de umidade, acelerando a secagem dos combustíveis. Ventos leves auxiliam certos materiais em brasa a dar início ao fogo. Uma vez iniciado o fogo, o vento auxilia a combustão pelo aumento do suprimento de oxigênio. $O$ vento alastra o fogo através do transporte de materiais acesos ou aquecidos para novos locais e inclina as chamas para perto dos combustíveis não queimados que estão na frente do fogo. A direção da propagação é determinada principalmente pelo vento (BROWN \& DAVIS, 1973).

Embora o comportamento do fogo seja afetado diretamente pela temperatura, a maioria dos efeitos são indiretos. Quanto mais aquecido o ar e as partículas de combustível, menor a quantidade de calor necessária para iniciar e continuar o processo (SOARES, 1985).

A umidade atmosférica é, isoladamente um dos fatores mais importantes na propagação dos incêndios florestais. Existe uma troca contínua de vapor d'água entre a atmosfera e o combustível depositado no piso da floresta. O material seco absorve umidade de uma atmosfera úmida e libera água quando o ar está seco. A quantidade de vapor d'água (umidade) que o material morto pode absorver do ar e reter dependem, basicamente da umidade do ar. A umidade atmosférica é também um elemento importante na avaliação do grau de dificuldade de combate aos incêndios. Dados sobre ocorrências de incêndios florestais demonstram que quando a umidade relativa do ar desce ao nível de $30 \%$ ou menos, torna-se extremamente difícil combater um incêndio (GAYLOR, 1974; BATISTA, 1984).

As precipitações são importantes porque ao manter o material florestal úmido, dificultam ou tornam impossível o início e a propagação do fogo. Existe uma forte correlação entre incêndios e prolongados períodos de seca. Nestes 
períodos de seca prolongada o material cede umidade ao ambiente, tornando as condições extremamente favoráveis às ocorrências de incêndios. Na avaliação do efeito da precipitação, deve-se considerar não apenas a quantidade de chuva que cai, mas também sua distribuição estacional. Se a distribuição das chuvas em um determinado local é uniforme durante todo o ano, sem uma estação seca definida, o potencial de ocorrência e propagação dos incêndios é menor do que um local onde a estação chuvosa está concentrada em alguns meses, com longos períodos de estiagem durante os outros meses. A distribuição da precipitação é, portanto fator fundamental na definição do início, término e duração da estação de perigo de fogo (SCHROEDER \& BUCK, 1970; SOARES, 1985).

\section{TOPOGRAFIA}

Costuma-se dizer que a topografia faz o clima e determina o tipo de combustível em uma determinada área. Considerando-se que o comportamento do fogo é em grande parte o resultado do clima e do combustível disponível, pode-se dizer que a topografia também influi decisivamente no comportamento do fogo. A topografia afeta profundamente as características dos ventos, particularmente os ventos convectivos. Além disso, é responsável pela localização dos diversos tipos de combustíveis, tendo influência sobre o seu crescimento e inflamabilidade devido os seus efeitos sobre o clima (GAYLOR, 1974).

\section{- $\quad$ TIPO DE COBERTURA VEGETAL}

O tipo de cobertura florestal influencia o comportamento do fogo de várias formas. A variação na cobertura vegetal implica em mudanças de diversos aspectos relacionados com o comportamento do fogo, principalmente combustível e condições climáticas. As propriedades dos combustíveis variam consideravelmente com o tipo de floresta. E as variações no combustível podem causar mudanças pronunciadas no comportamento do fogo. Uma floresta densa, fechada, proporciona um microclima mais ameno e os combustíveis apresentam um conteúdo de umidade maior e mais estável do que uma floresta rala ou aberta. Deste modo, pode-se afirmar que o fogo se propaga com mais facilidade na floresta aberta do que na densa. Da mesma forma, de modo geral, uma floresta de coníferas apresenta condições mais propícias para a propagação do fogo do que uma de folhosas. (SOARES \& BATISTA, 1997).

\section{MAPAS TEMÁTICOS}

A análise detalhada e criteriosa de cada variável associada ao risco de incêndios permite estabelecer graus ou níveis de risco, de acordo com a 
influência maior ou menor dessa variável sobre a ignição e a propagação do fogo em cada local considerado. Desta forma é possível se construir mapas temáticos de risco de incêndios para uma determinada região, associando-se a variável - fonte de fogo ou fator de propagação - ao risco potencial de incêndios florestais. Portanto, a partir de um mapa base pode se elaborar cartas temáticas sobre o risco de incêndios. Por exemplo: pode-se construir para uma determinada região um mapa de risco de incêndios com base na declividade do terreno, outro mapa de risco com base no tipo de vegetação, outro com base nas condições meteorológicas, outro com base no nível de antropismo,...E assim por diante, pode se construir tantos mapas quantas variáveis associadas ao risco de incêndios forem avaliadas.

Definir os níveis de risco de incêndios para cada variável analisada é a parte mais importante e também a que oferece maior dificuldade na elaboração do zoneamento. Nessa fase é fundamental o conhecimento sobre as ocorrências de incêndios no passado da região em estudo ou sobre regiões que apresentam condições similares. É fundamental também obter o máximo de informações sobre as pesquisas do comportamento do fogo em regiões semelhantes a fim de facilitar o trabalho de definição dos níveis de risco. Fotografias aéreas com apoio de campo são também elementos básicos tanto para caracterização das variáveis quanto para definição dos níveis de risco.

\section{MAPA DE RISCO}

A etapa final do zoneamento é a elaboração de um mapa de risco, resultante da superposição dos vários mapas temáticos desenvolvidos na etapa anterior. Na realidade, o mapa não consiste da simples superposição dos mapas temáticos, mas da delimitação de áreas de acordo com nível de risco em função da somatória ponderada dos riscos parciais de cada variável analisada na etapa anterior. Portanto, para a elaboração do mapa final de zoneamento é necessário desenvolver um algoritmo ou um modelo matemático que expresse numericamente a interação de todas as variáveis analisadas na influência que exercem sobre o início e a propagação do fogo. Esses modelos devem ser desenvolvidos com base em informações bibliográficas e levantamento de campo, de forma que possam representar o mais fielmente possível a influência ponderada de cada variável no risco de incêndios para a região ou local considerado.

Para manipular documentos cartográficos, pode-se utilizar um sistema de informações geográficas (SIG). O SIG é um banco de dados geocodificado que armazena, gerencia, recupera e processa informações digitais georreferenciadas, provenientes de imagens, mapas, dados estatísticos e descritivos. O ambiente computacional permite analisar dados de forma integrada, com o objetivo de obtenção de soluções rápidas e precisas, para 
problemas relacionados com o comportamento espacial dos dados (GTZ, 1994; BÄHR \& VÖGHTLE, 1991).

A computação gráfica do SIG permite visualizar estatisticamente respostas na forma de mapas, diagramas ou desenhos que revelam conseqüências de estratégias propostas no tempo. Embora a cartografia automatizada seja a base do SIG, foi necessário também desenvolver um braço computacional para atender a necessidade de integrar, analisar e criar informação. Pela abundância de dados e análises complexas, foram desenvolvidos algoritmos espaciais e modelos computacionais específicos. O SIG supre com ferramenta e métodos para combinar ou integrar estes dados, em um formato que possibilita sua comparação. Assim como é possível analisar informações espaciais para extrair conhecimento, também é possível usar relacionamentos conhecidos para modelar geograficamente a saída ou predizer o produto de um conjunto de condições (SEIFERT, 1996).

\section{CONSIDERAÇÕES GERAIS}

A elaboração de um mapa de risco de incêndios florestais a princípio parece complexa por envolver a necessidade de um conjunto diversificado de variáveis do ambiente a ser mapeado. No entanto, grande parte das informações necessárias ao estudo e elaboração do zoneamento são dados necessários a qualquer tipo de planejamento do manejo dos recursos naturais e por isso já estão (ou deveriam estar) disponibilizados para a maioria das áreas florestais de administração pública ou privada, como por exemplo: levantamentos planialtimétricos, sobre a cobertura vegetal, sobre alterações antrópicas normal climatológicas, etc. Basta ter acesso a essas informações e processá-las adequadamente para gerar os mapas temáticos, que posteriormente serão ponderados para a elaboração do mapa de riscos de incêndios.

Depois de elaborado, o mapa de riscos pode ser atualizado periodicamente em função das alterações ambientais que ocorrem ao longo do tempo, como por exemplo: alterações da cobertura vegetal (desmatamento), características do material combustível (quantidade e tipo), condições climáticas estacionais, etc. É possível também avaliar a eficiência do zoneamento através da análise dos registros de ocorrências de incêndios, alguns anos após a elaboração do mapa de riscos.

\section{BIBLIOGRAFIA CITADA}

ALMEIDA, R. Forest Fire Risk Areas and Definition of the Prevention Priority Planning Actions Using Gis.

1994 , wwwsgi.ursus.maine.edu/gisweb/spatdb/egis/eg94193.html

ANDERSON, H. E. \& BROWN, J. K. Fuel characteristics and fire behavior considerations on the wildlands. In: Protecting people and homes from wildfires in the 
interior west. Proceedings of yhe Symposium and Workshop, Misooula, Int. Res. Station. Gen. Tech. Report - 251, 1988. p.124-130.

BÄHR, H, P, \& VÖGTLE, T, Digitale bildverarbeitung: Andwendung in Photogrammetrie, Kartographie Und Fernerkundung, Karlsruhe, Wichmann, 1991, $328 \mathrm{p}$.

BATISTA, A. C. Determinação de umidade do material combustível sob povoamentos de Pinus taeda. Curitiba, Universidade Federal do Paraná, 1984. 61p. (Dissertação de mestrado).

BATISTA, A. C. Incêndios Florestais. Imprensa Universitária da Universidade Federal Rural de Pernambuco, Recife, 1990, 115p.

BROWN, A. A. \& DAVIS, K. P. Forest Fire - Control and Use. New York, McGraw Hill, 2nd Ed., 1973. 686p.

CHANDLER, C. CHENEY, P. THOMAS, P. TRABAUD, L. WILLIAMS, D. Fire in Forestry. 2, John Wiley \& Sons, New York.1983. 450p.

CHOU, Y. MINNICH, R. A. SALAZAR, L. A. POWER, J. D. DEZZANI, R. J. Spatial Autocorrelation Of Wildfire Distribution In The Idyllwild Quadrangle, San Jacinto Mountais, California. 1990. Photogrammetric Engineering \& Remote Sensing, 56:11, 1507-1513.

GAYLOR, H. P. Wildfires - Prevention And Control. Robert J. Brady, Bowie, 1974. 319p.

GTZ, Geographische Informationsysteme, Eschborn, GTZ, 1994, 99p.

MACEDO, F. W. \& SARDINHA A. M. Fogos Florestais. Universidade de Trás-osMontes e Alto Douro, v.2, 1987, 430p.

RIGOLOT, E. Combustíveis. In: REGO, F. C. \& BOTELHO, H. S. A técnica do fogo controlado. Universidade de Trás-Os-Montes e Alto Douro, Trás-Os-Montes, 1990, pg. $35-38$.

SALAS, J. \& CHUVIECO, E. Geographic Information Systems for Wildland Fire Risk Mapping. Wildfires 1994, 3: 2, 7-13.

SCHROEDER, M. J. \& BUCK, C. C. Fire weather - A guide for application of meteorological information to forest fire control operations. U.S. D. A. Handbook 360, 1970. 229p. 
SEIFFERT, N. F. Uma contribuição ao processo de otimização do uso dos recursos naturais em micro bacias hidrográficas. Universidade Federal de Santa Catarina. Tese submetida à Universidade Federal de Santa Catarina para a obtenção do título de Doutor em Engenharia de Produção. 1996.

http://www.eps.ufsc.br/teses96/seiffert/cap2/cap2_nel.htm.

SHOW, S. B. \& CLARKE, B. La lucha contras los incendios forestales. Roma, FAO. 1953. 131p.

SMITH, D. T. 1999. Mapping the bushfire danger of Hobart. Australian Bushfire Conference, Albury, July 1999. http://life.csu.edu.au/bushfire99/contents.html.

SOARES, R. V. Incêndios Florestais - Controle e Uso do fogo. Curitiba, FUPEF, 1985. 213p.

SOARES, R. V. Planos de Proteção contra incêndios florestais. In: IV reunião Técnica Conjunta FUPEF/SIF/IPEF e II Curso de Atualização em Controle de Incêndios Florestais, 1996. ANAIS, p. 140-150.

SOARES, R.V. \& BATISTA, A. C. Manual de prevenção e combate a incêndios florestais. Curitiba, Convênio IAP/FUPEF, 1997. 50p.

SOUSA, C. PINHEIRO, D. GRILO, F. GUERREIRO, J. MENDONÇA, M. CARIDADE, M. L. CASTRO, M. MESQUITA, P. ALMEIDA, R. 1996. Relatório do Projecto de Cartografia de Risco de Incêndio Florestal - CRIF $2^{\mathrm{a}}$ Fase. www.terravista.pt 